\title{
Investigation of Fluorescent Shape Memory Polyurethanes Grafted with Various Dyes ${ }^{\dagger}$
}

\author{
Yong-Chan Chung, ${ }^{\ddagger}$ Jae Won Choi, Seung Hwan Lee, and Byoung Chul Chun ${ }^{\S^{*}}$ \\ Department of Polymer Engineering, University of Suwon, Hwasung 445-743, Korea \\ Department of Chemistry, University of Suwon, Hwasung 445-743, Korea \\ ${ }^{\S}$ School of Nano Engineering, Center for Nano Manufacturing, Institute of Basic Science, Inje University, Gimhae 621-749, Korea \\ "E-mail: bcchun@inje.ac.kr
}

Received February 8, 2011, Accepted April 13, 2011

\begin{abstract}
Shape memory polyurethane (SMPU), grafted with a fluorescent dye (Rhodamine, Mehylene violet, or Fluorescein) through an allophanate linking, was tested for the fluorescence and the shape recovery effect. The main chain of SMPU was composed of 4,4'-methylenebis(phenylisocyanate) (MDI), poly(tetramethyleneglycol) (PTMG), and 1,4-butanediol (BD), and a fluorescent dye was connected through a second MDI linked to the carbamate moiety of the main chain. Three series of SMPU, differing according to their dye content, were prepared to compare their shape recovery and fluorescence properties. In tensile mechanical property, maximum stress increased up to $350 \%$ compared to the linear SMPU, and strain remained above $2000 \%$. Shape recovery went to as high as $97 \%$, and remained almost same after repetitive shape recovery test cycles. Finally, the fluorescence emission of SMPU was demonstrated in the luminescence spectrum and fluorescent light emission pictures. In addition, the response of SMPU to external stimuli such as metal ions was investigated.
\end{abstract}

Key Words : Fluorescence, Polyurethane, Grafting, Shape memory

\section{Introduction}

Shape memory polyurethane (SMPU) has drawn a wide attention among the smart polymers due to the exceptional properties such as excellent tensile strain, reproducible shape recovery, easy modification and functionalization, and high industrial demand in coating and textile. ${ }^{1-7}$ Many structural modifications of SMPU such as flexible cross-linking method were tried to simultaneously improve both tensile mechanical and shape memory properties without a decrease in tensile strain. ${ }^{8-12}$ In addition to the improvement in above properties, special effects such as electric or magnetic response, metal ion sensing, low temperature shape recovery, temperature or $\mathrm{pH}$-sensing, and electric conductivity can be endowed to SMPU chains through the covalent coupling of functional molecules. For example, a SMPU that can sustain shape recovery even at $-30{ }^{\circ} \mathrm{C}$ has been reported..$^{13}$ An electroactive shape memory polymer composite containing carbon nanotube, ${ }^{14,15}$ electromagnetic filler, ${ }^{16,17} \mathrm{Ni}$ chain, ${ }^{18,19}$ have been already reported, demonstrating a quick shape recovery according to the application of electric current or electromagnetic field. In line with the above functional polymers, three well known fluorescent dyes, rhodamine, methylene violet, or fluorescein, were grafted to SMPU chain in this investigation to synthesize various fluorescent SMPUs as chemosensors. Rhodamine and the derivatives, known as fluorophore and chromophore, were famous as chemosensor in detecting heavy and transition metal ions. ${ }^{20,21}$ Rhodamine could be grafted to polymer matrix such as cellulose for affinity chromatography, ${ }^{22}$ poly

This paper is dedicated to Professor Eun Lee on the occasion of his honourable retirement. (methylmeta acrylate) for photostability of rhodamine as laser dye, ${ }^{23,24}$ and inorganic silica for the stabilization of photo spectrum shift. ${ }^{25}$ The fluorescence traceability of rhodamine was applied to a supramagnetic nanocomposite. ${ }^{26}$ Methylene violet, a phenazine dye, was used for photo inactivation of bacteria and virus in blood through DNA binding. ${ }^{27,28}$ Fluorescein and its derivatives were widely used as chemosensors for $\mathrm{Hg}^{2+},{ }^{29} \mathrm{Zn}^{2+}$, ${ }^{30}$ pyrophosphate, ${ }^{31} \mathrm{~F}^{-32}$ and $\mathrm{pH}$ change. ${ }^{33} \mathrm{It}$ was coupled to poly(vinyl alcohol) to make water-soluble $\mathrm{pH}$ and temperature sensitive polymer, ${ }^{34}$ and was labeled to block copolymer to study skin penetration of biodegradable polymer. ${ }^{35}$ Furthermore, fluorescein was attached to polyester backbone for light emitting polymer, ${ }^{36}$ and poly(allylamine) for electro potential responsive thin film. ${ }^{37}$ In this investigation, SMPU that contained fluorescent dyes grafted to polymer backbone was researched, because this type of fluorescent SMPU was not reported, and could have potential applications in detecting any surrounding change in metal ion concentration, $\mathrm{pH}$, or temperature and to signal the difference by shifting its emission wavelength.

\section{Experimental}

Materials. Poly(tetramethyleneglycol) (PTMG, Aldrich, Mw $=2,000 \mathrm{~g} / \mathrm{mol}$ ), 4,4'-methylenebis(phenylisocyanate) (MDI, Tokyo Kasei), and 1,4-butanediol (BD, Junsei Chemical) were dried under high vacuum ( 0.1 torr) for $10 \mathrm{hrs}$ before use. Fluorescent dyes (rhodamine, mehylene violet, and fluorescein) were obtained from Aldrich Chemical, and used after drying under vacuum. Dimethylformamide (DMF, Duksan Chemical, Korea) and dimethylacetamide (DMAC, Duksan Chemical) were distilled over $\mathrm{CaH}_{2}$ before use. 
Polymer Synthesis. A mixture of MDI and PTMG with a ratio specified in Table 1 was placed in a $500-\mathrm{mL}$ fournecked beaker-type flask equipped with a mechanical stirrer, condenser, nitrogen purge, and oil bath. The mixture was allowed to react for $3 \mathrm{hrs}$ at $50^{\circ} \mathrm{C}$ to prepare the prepolymer. $\mathrm{BD}$, functioning as a chain extender, was dissolved in 100 $\mathrm{mL}$ of DMF and added to the prepolymer, and the reaction continued for $1 \mathrm{hr}$. Subsequently, a second quantity of MDI was added to the above reaction mixture, and the reaction continued for $1 \mathrm{hr}$. Finally, the dye dissolved in $50 \mathrm{~mL}$ of DMF was added into the reaction mixture. This mixture was stirred under the same conditions for $2 \mathrm{hrs}$. As a control, linear SMPU without dye was prepared. After polymerization ended, the polyurethane product was dried in a $60{ }^{\circ} \mathrm{C}$ oven for 3 days to remove residual DMF, and rinsed in chloroform to remove free dyes. Schematics of the resulting SMPU structures are shown in Figure 1. Specimens for mechanical testing were prepared by the solvent casting method. In particular, a solution of SMPU in DMF was slowly evaporated at $70{ }^{\circ} \mathrm{C}$ for $60 \mathrm{hrs}$ to obtain a $0.7-0.9-\mathrm{mm}$-thick PU sheet. Specimens were prepared from the sheet according to ASTM D638.

Cross Link Density. A specimen with dimensions $20 \times$ $20 \times 1 \mathrm{~mm}$ and a known weight $\left(\mathrm{m}_{1}\right)$ was swollen in $50 \mathrm{~mL}$ of toluene in a closed cap bottle for $24 \mathrm{hrs}$, and the swollen weight of the specimen $\left(\mathrm{m}_{2}\right)$ was measured after quickly removing the adsorbed toluene from the polymer surface with a tissue. The swollen specimen was dried at room temperature for a week, and the dry weight of the specimen was then measured $\left(\mathrm{m}_{3}\right)$. The solvent volume $\left(\mathrm{V}_{\mathrm{s}}\right)$ in a swollen specimen, averaged over five swelling experiments, was calculated using the weight difference between the swollen $\left(\mathrm{m}_{2}\right)$ and dry states $\left(\mathrm{m}_{3}\right)$ and the solvent density $(0.8699 \mathrm{~g} /$ $\left.\mathrm{cm}^{3}\right)$. The volume of the polymer $\left(\mathrm{V}_{\mathrm{p}}\right)$ in its dry state was calculated by dividing the polymer dry weight $\left(\mathrm{m}_{1}\right)$ by the polymer density. The volume fraction of polymer in the

Table 1. Composition of the Fluorescent SMPU

\begin{tabular}{cccccc}
\hline \multirow{2}{*}{$\begin{array}{c}\text { Sample } \\
\text { Code }\end{array}$} & \multicolumn{4}{c}{ Reactant, mmol } \\
\cline { 2 - 5 } & MDI-1 & PTMG & BD & MDI-2 & Dye \\
\hline R-1 & & & 30 & 0.40 & 0.020 \\
R-2 & & & 30 & 1.0 & 0.050 \\
R-3 & \multirow{2}{*}{20} & 30 & 2.0 & 0.10 \\
R-4 & & & 30 & 3.0 & 0.15 \\
R-5 & & & 30 & 4.0 & 0.20 \\
\hline M-1 & & & 30 & 0.52 & 0.026 \\
M-2 & & & 30 & 1.3 & 0.065 \\
M-3 & 50 & 20 & 30 & 2.6 & 0.13 \\
M-4 & & & 30 & 3.8 & 0.19 \\
M-5 & & & 30 & 5.2 & 0.26 \\
\hline F-1 & & & 30 & 0.62 & 0.031 \\
F-2 & & & 30 & 1.5 & 0.077 \\
F-3 & 50 & 20 & 30 & 3.1 & 0.16 \\
F-4 & & & 30 & 4.6 & 0.23 \\
F-5 & & & 30 & 6.2 & 0.31 \\
\hline
\end{tabular}

swollen mass $\left(\mathrm{v}_{1}\right)$ was calculated using the equation $\mathrm{V}_{\mathrm{p}} /\left(\mathrm{V}_{\mathrm{s}}\right.$ $\left.+V_{p}\right)$. The derivation of the cross-link density is described in the result section.

Characterization. A Fourier-transform infrared (FT-IR) spectrophotometer (JASCO 300E) equipped with attenuated total reflectance capability was used to take infrared spectra of the SMPU samples. For each sample, 25 scans were taken at $4 \mathrm{~cm}^{-1}$ resolution and a $2 \mathrm{~mm} / \mathrm{s}$ scan speed. A differential scanning calorimeter (DSC 8000, Perkin Elmer) was used to take calorimetry data for both heating and cooling scans at a rate of $10^{\circ} \mathrm{C} / \mathrm{min}$ between -50 and $250^{\circ} \mathrm{C}$. After melting at $250{ }^{\circ} \mathrm{C}$ for 5 minutes and cooling quickly to $-50{ }^{\circ} \mathrm{C}$, a $20 \mathrm{mg}$ specimen was warmed to $250^{\circ} \mathrm{C}$ at $10{ }^{\circ} \mathrm{C} /$ minute while monitoring the phase transition. Tensile mechanical properties were measured with a Universal Testing Machine (UTM, LR50K, Lloyd instrument, UK) according to the ASTM D638 standard with a $25 \mathrm{~mm}$ gauge length, a $10 \mathrm{~mm} / \mathrm{min}$ crosshead speed, and a $2.5 \mathrm{kN}$ load cell. Viscosity, an average of three experiments, was obtained by a viscometer (AND SV-10) for SMPU dissolved in DMAC at five different concentrations $(0.25,0.50,1.0,2.0$, and $4.0 \%(\mathrm{w} / \mathrm{w}))$ at $25^{\circ} \mathrm{C} . \mathrm{H}-$ NMR ( $\left.\mathrm{CF}_{3} \mathrm{COOD}\right)$ spectrum of R-5 was taken by a VarianUnity Inova $500 \mathrm{NB}$ spectrometer $(500 \mathrm{MHz}): 1.67 \mathrm{ppm}$ $\left(\mathrm{CH}_{2} \mathrm{CH}_{2} \mathrm{CH}_{2} \mathrm{CH}_{2} \mathrm{O}\right)_{\mathrm{n}}, 1.92 \mathrm{ppm} \mathrm{CH}_{2} \mathrm{CH}_{2} \mathrm{CH}_{2} \mathrm{CH}_{2} \mathrm{O}, 3.65$ ppm $\left(\mathrm{CH}_{2} \mathrm{CH}_{2} \mathrm{CH}_{2} \mathrm{CH}_{2} \mathrm{O}\right)_{\mathrm{n}}, 3.88 \mathrm{ppm} \mathrm{CH}_{2} \mathrm{CH}_{2} \mathrm{CH}_{2} \mathrm{CH}_{2} \mathrm{O}$, $4.20 \mathrm{ppm}\left(\mathrm{PhCH} \mathrm{H}_{2} \mathrm{Ph}\right.$ ), $4.77 \mathrm{ppm}$ (NHCOO), $7.05 \mathrm{ppm}$ (MDI aromatic), and 8.08 (Rhodamine). Other SMPU series NMR spectra also showed the similar shape as the above one. Fluorescence spectra were obtained by a Perkin-Elmer LS50B Luminescence spectrometer, and luminescence test between 254 and $366 \mathrm{~nm}$ was carried out by a luminescence detector (Atto SO-1031A, Japan).

Shape Memory Test. A UTM equipped with a temperaturecontrolled chamber was used for cyclic shape memory tests. The method for these tests is illustrated in Figure 2. A specimen with a length $\mathrm{L}_{0}$ was drawn $100 \%$ to $2 \mathrm{~L}_{0}$ in a temperature-controlled chamber set at $45^{\circ} \mathrm{C}$ over the course of 2 minutes and kept at $45{ }^{\circ} \mathrm{C}$ for 5 minutes. Afterwards, the specimen in the chamber was cooled to $-25{ }^{\circ} \mathrm{C}$ with liquid nitrogen for 10 minutes, and the upper grip was released. The shrunken length $\left(\mathrm{L}_{1}\right)$ was measured after the sample had remained at $-25{ }^{\circ} \mathrm{C}$ for 20 minutes. Percent shape retention (\%) was calculated using equation (1), $\mathrm{L}_{0}$, and $\mathrm{L}_{1}$. The specimen in the chamber was heated to $45^{\circ} \mathrm{C}$ for 5 minutes, and the length $\left(\mathrm{L}_{2}\right)$ was measured after 10 minutes at $45^{\circ} \mathrm{C}$. Percent shape recovery (\%) was calculated using equation (2), $2 \mathrm{~L}_{0}$, and $\mathrm{L}_{2}$. The shape memory test was repeated three times for each specimen.

$$
\begin{aligned}
& \text { Shape retention }=\left(\mathrm{L}_{1}-\mathrm{L}_{\mathrm{o}}\right) \times 100 / \mathrm{L}_{\mathrm{o}}(\%) \\
& \text { Shape recovery }=\left(2 \mathrm{~L}_{\mathrm{o}}-\mathrm{L}_{2}\right) \times 100 / \mathrm{L}_{\mathrm{o}}(\%)
\end{aligned}
$$

\section{Results and Discussion}

Synthesis and the Structure of SMPU. The characteristic SMPU structure originated from hard (MDI) and soft (PTMG) segment, and the hard segment could be used as the site for 
(a)

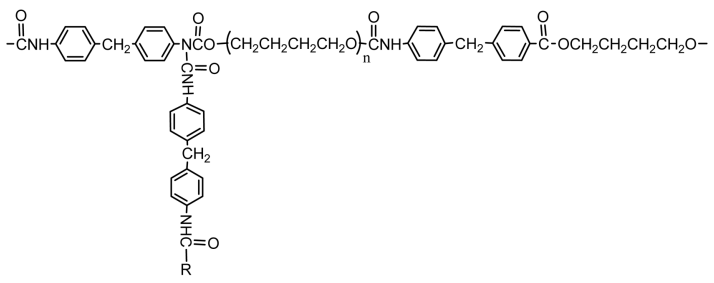

(b)

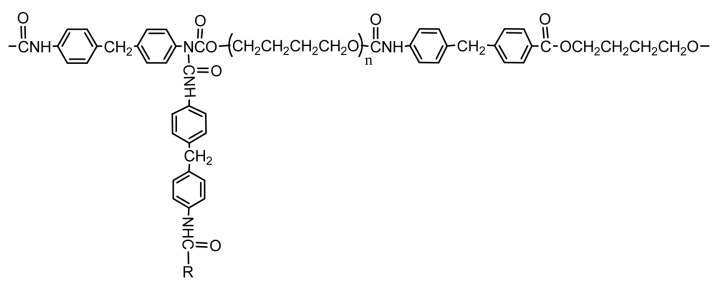

(c)

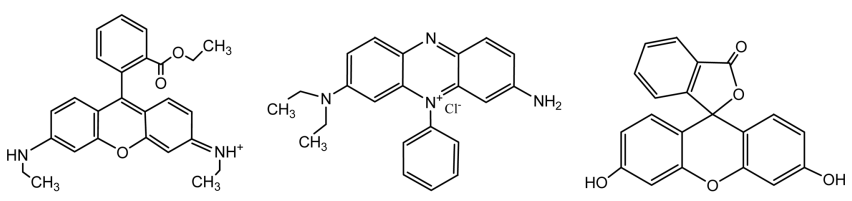

Figure 1. Structures of (a) grafted SMPU ( $R$ is the point for dye linking), (b) MDI mediated cross-linked SMPU, (c) rhodamine, (d) methylene violet, and (e) fluorescein.

grafting functional molecules or cross-linking with other PU chains. The grafting of functional molecules to SMPU backbone was based on the references ${ }^{38-40}$ and our research finding that a flexible cross-linker such as PEG could be successfully linked to the middle of PU chains through a lateral linking method. ${ }^{11,12}$ In a similar vein, a fluorescent dye was grafted to SMPU chain through a second MDI that connected the SMPU and fluorescent dye by allophanate bonding. The allophanate linking was advantageous in that a reactive amino group was used as a linking site, and the carbamate group for allohphanate bonding was evenly distributed along the PU chain for linking. The structures of dye-grafted SMPU can be observed in Figure 1 in which the dyes selected for this research have either amino (rhodamine and methylene violet) or hydroxyl (fluorescein) as a nucleophilic group. Because excess second MDI was used for complete dye grafting and extra MDI could connect each SMPU chains as in the Figure 1(b), SMPU chains were laterally linked by MDI at various sites along the polymer chain and its overall mechanical strength could be improved compared with the linear one. The representative NMR spectrum of R-5 (Figure 3) agreed well with the proposed SMPU structure, and other SMPU series showed similar spectra. In Table 1, the content of dye increased gradually as the sample number increased at a constant soft segment (PTMG) content.

IR and Thermal Analysis. The stretching vibrational mode of the hydrogen bonded urethane carbonyl group appeared in the IR spectrum at $1699-1706 \mathrm{~cm}^{-1}$, at slightly lower wave number than that of the free urethane carbonyl group (1731-1733 $\left.\mathrm{cm}^{-1}\right){ }^{41}$ The stretching vibrational mode of the carbonyl group is also affected by dipole-dipole interactions between SMPU chains. The peaks around both 1700

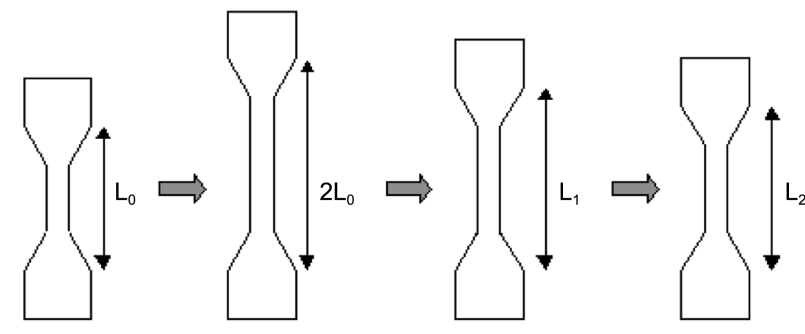

Figure 2. A test specimen for shape retention and recovery (where $\mathrm{L}_{0}$ is the initial specimen length, $2 \mathrm{~L}_{0}$ is the length of $\mathrm{L}_{0}$ strained $100 \%$ above $T_{m}, L_{1}$ is the deformed length below $T_{m}$ after load removal, and $\mathrm{L}_{2}$ is the final specimen length above $\mathrm{T}_{\mathrm{m}}$ ).

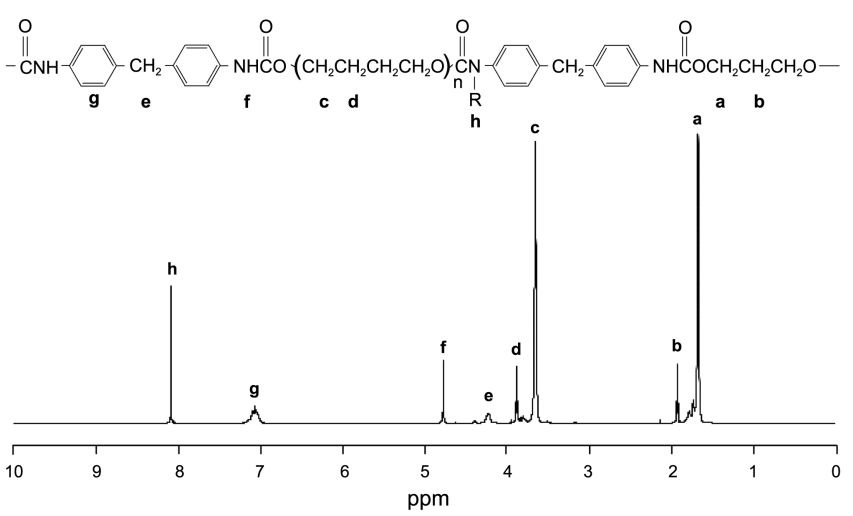

Figure 3. ${ }^{1} \mathrm{H}-\mathrm{NMR}$ spectrum of R-5

$\mathrm{cm}^{-1}$ and $1730 \mathrm{~cm}^{-1}$ did not change with increasing dye content for all of R, M, and F series (Figure 4). Based on the IR results for all of $\mathrm{R}, \mathrm{M}$, and $\mathrm{F}$ series, grafting of dye did not seem to affect molecular interactions such as hydrogen bonding and dipole-dipole interactions, and hard segment interactions were not disrupted. The glass transition temperature $\left(\mathrm{T}_{\mathrm{g}}\right)$ of a soft segment of SMPU, the PTMG section, was low (below $-50{ }^{\circ} \mathrm{C}$ ) and difficult to detect by DSC, so instead the melting temperature $\left(\mathrm{T}_{\mathrm{m}}\right)$ of this soft segment of SMPU was sought. The $T_{m}$ of soft segments, although small, was observed around $20^{\circ} \mathrm{C}$ in the first heating scan (Figure $5(\mathrm{a})$ ), but disappeared in the second heating scan (Figure 5 (b)). The soft segment melting temperature was slightly decreased, considering the fact that the $T_{m}$ of pure PTMG was $28-40{ }^{\circ} \mathrm{C}$, because hydrogen bonding between pure PTMG molecules was significantly reduced after PTMG was connected in the SMPU chains. The thermal analysis results suggested that the soft segment melting peak of SMPU was minimal and soft segment was freely moving, considering the low energy barrier for melting, although fluorescent dyes were attached.

Cross Link Density. Cross-link density was calculated from the polymer swelling experiment to know how much cross-linking was formed during dye grafting to SMPU chain compared to linear one. The interaction parameters $(\chi)$ between solvent and polymer were determined from the following expression: ${ }^{42}$

$$
\chi=\left(\delta_{1}-\delta_{2}\right)^{2} \mathrm{~V}_{1} / \mathrm{RT}
$$


(a)

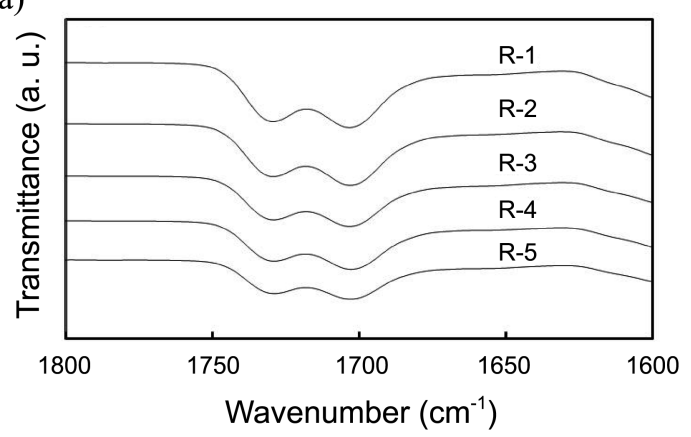

(b)

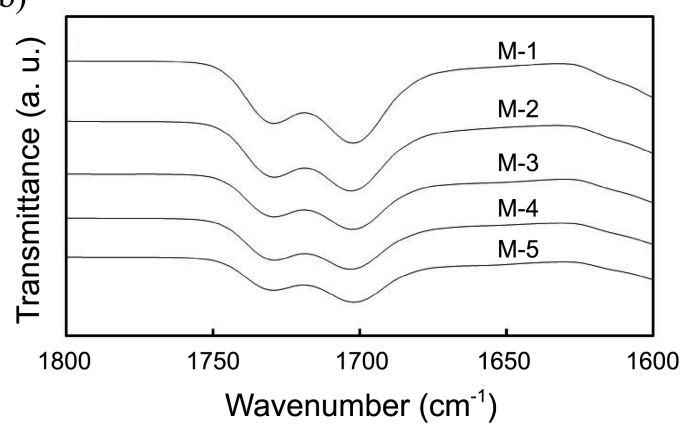

(c)

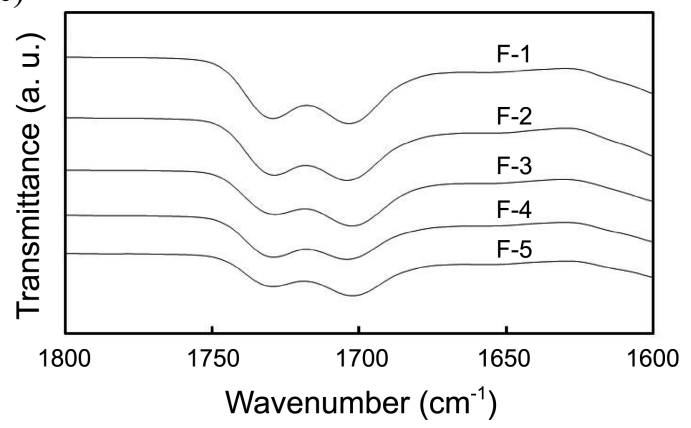

Figure 4. IR spectra of the (a) R, (b) M, and (c) F series.

$\delta_{1}$ and $\delta_{2}=$ solubility parameter of solvent and polymer

$\mathrm{V}_{1}=$ molar volume of solvent $\left(106.3 \mathrm{~cm}^{3} / \mathrm{mol}\right)$

$\mathrm{R}=$ gas constant $\left(8.31 \mathrm{MPa} \cdot \mathrm{cm}^{3} \cdot \mathrm{K}^{-1} \cdot \mathrm{mol}^{-1}\right)$

$\mathrm{T}=$ absolute temperature $(298 \mathrm{~K})$

The solubility parameters of toluene $\left(\delta_{1}\right)$ and PU $\left(\delta_{2}\right)$ were 18.2 and $20.5(\mathrm{MPa})^{1 / 2}$, respectively. ${ }^{43,44}$ The degree of crosslinking was calculated from Flory-Rehner equation (4):

$$
-\left[\ln \left(1-\mathrm{v}_{2}\right)+\mathrm{v}_{2}+\chi \mathrm{v}_{2}^{2}\right]=\mathrm{V}_{1} \mathrm{n}\left[\mathrm{v}_{2}-1 / 2 \mathrm{v}_{2}\right]
$$

$\mathrm{v}_{2}=$ volume fraction of polymer in the swollen mass

$\chi=$ interaction parameter

$\mathrm{n}=$ cross-link density

Cross-link density slightly increased with increasing dye content, which suggested that the extra second MDI contributed to cross-linking SMPU chains (Table 2). It seems that dye was quantatively grafted to SMPU chains because excess second MDI compared to dye content was used in the synthesis, and the extra MDI was not wasted considering the increase in cross-link density.

Viscosity. The viscosity of SMPU dissolved in DMAC was investigated, under the theory that polymer chains in the
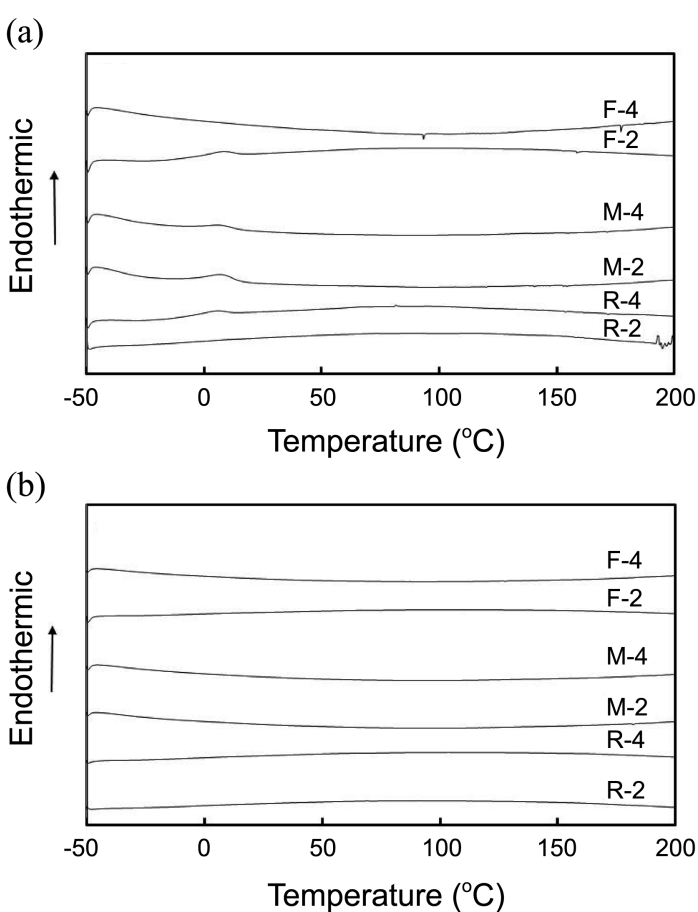

Figure 5. DSC thermograms of (a) first heating scan and (b) second heating scan.

Table 2. Cross-link density of SMPU determined by swelling experiments

\begin{tabular}{ccccc}
\hline $\begin{array}{c}\text { Sample } \\
\text { Code }\end{array}$ & $\begin{array}{c}{ }^{a} \rho \\
\left(\mathrm{g} / \mathrm{cm}^{3}\right)\end{array}$ & $\begin{array}{c}{ }^{b} \mathrm{~V}_{\mathrm{p}} \\
\left(\mathrm{cm}^{3}\right)\end{array}$ & ${ }^{c} \mathrm{~V}_{2}$ & $\begin{array}{c}{ }^{d} 10^{3} \mathrm{n} \\
\left(\mathrm{mole} / \mathrm{cm}^{3}\right)\end{array}$ \\
\hline R-1 & 0.980 & 0.252 & 0.324 & 0.798 \\
R-2 & 0.990 & 0.279 & 0.345 & 0.910 \\
R-3 & 1.08 & 0.260 & 0.431 & 1.13 \\
R-4 & 0.926 & 0.266 & 0.387 & 1.20 \\
R-5 & 0.917 & 0.265 & 0.411 & 1.28 \\
\hline M-1 & 0.926 & 0.241 & 0.329 & 0.814 \\
M-2 & 0.952 & 0.291 & 0.351 & 0.958 \\
M-3 & 1.09 & 0.209 & 0.362 & 1.04 \\
M-4 & 1.05 & 0.266 & 0.397 & 1.29 \\
M-5 & 1.01 & 0.274 & 0.404 & 1.34 \\
\hline F-1 & 1.02 & 0.222 & 0.310 & 0.706 \\
F-2 & 1.05 & 0.174 & 0.358 & 0.805 \\
F-3 & 1.06 & 0.235 & 0.400 & 1.09 \\
F-4 & 1.03 & 0.178 & 0.379 & 1.15 \\
F-5 & 1.01 & 0.248 & 0.395 & 1.27
\end{tabular}

${ }^{a} \rho$ is the polymer density, ${ }^{b} \mathrm{v}_{\mathrm{p}}$ is the polymer volume, ${ }^{c} \mathrm{v}_{2}$ is the volume fraction of polymer, and ${ }^{d} \mathrm{n}$ is the cross-link density.

cross-linked structure could drag each other more than in linear PU and thus increase solution viscosity. Viscosity results showed an exponential increase in proportion to SMPU concentration, and the medium grafted SMPUs showed the highest viscosity instead of the highly grafted ones (Figure 6). Viscosity increase at low dye grafting was due to the hindrance of free chain movement by the grafted dyes. The decrease of viscosity at high dye grafting could be explained by the fact that high concentration of the grafted dye made 
repulsion between dyes and thus SMPU chains are less mingled between themselves reducing the viscosity. Therefore, the viscosity results suggested that dye grafting was formed, in proportion to the added amount of dye, along the SMPU chains.

Tensile Mechanical Properties. Maximum stress in the $\mathrm{R}$ series increased from $15 \mathrm{MPa}$ for R-1 to $33 \mathrm{MPa}$ for R-3 and then to $43 \mathrm{MPa}$ for R-5. Maximum stress in the $\mathrm{M}$ and $\mathrm{F}$ series also showed a significant increase, going from 12 MPa for M-1 and $13 \mathrm{MPa}$ for F-1, to $34 \mathrm{MPa}$ for M-3 and 35 $\mathrm{MPa}$ for F-3, and then to $33 \mathrm{MPa}$ for M-5 and $36 \mathrm{MPa}$ for F5 (Figure 7). The increase of tensile stress was due to the fact that extra second MDI was used for cross-linking instead of grafting dye and thus improved mechanical strength. Strain at break in the R series increased from $1191 \%$ for R-1 to $2874 \%$ for R-3, and then slightly decreased to $2351 \%$ for R5. Strain at break in the $\mathrm{M}$ and $\mathrm{F}$ series also showed a similar trend as the dye content increased: $1769 \%$ in M-1 and $1608 \%$ in F-1 were changed to $2719 \%$ in M-3 and $2342 \%$ in F-3 and finally $2527 \%$ in M-5 and $2018 \%$ of F-5 (Figure 8 ). It was found that strain at break of the SMPU did not decrease by the dye-grafting, although maximum stress was increased.

(a)

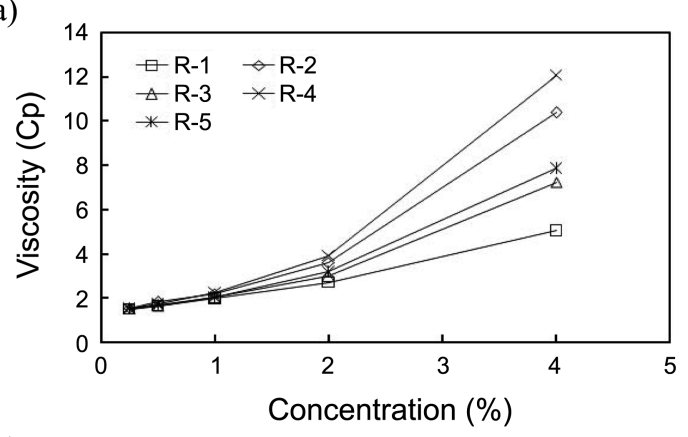

(b)

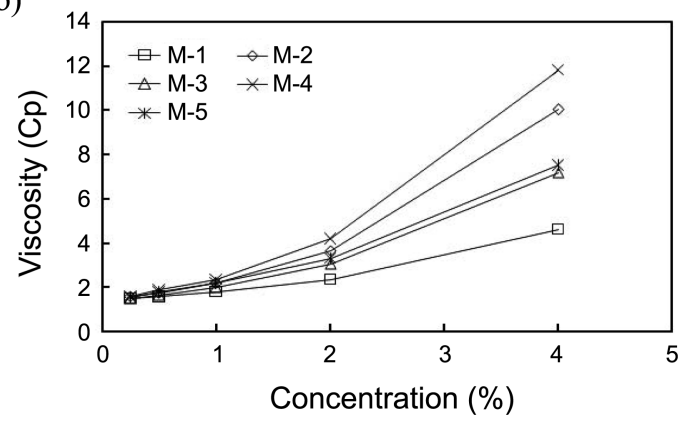

(c)

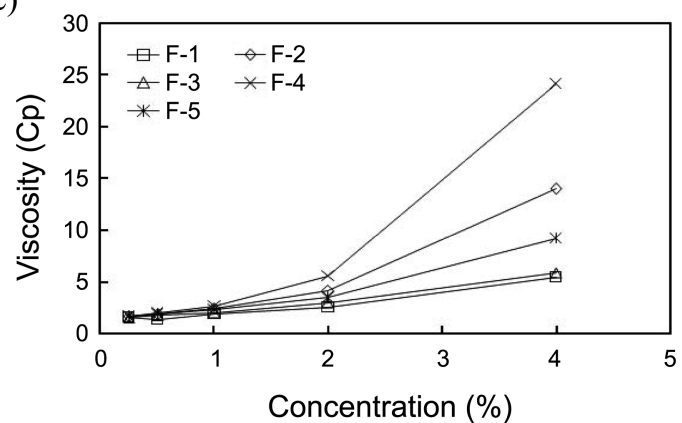

Figure 6. Viscosity vs. concentration profile of (a) R, (b) M, and (c) F series. (a)

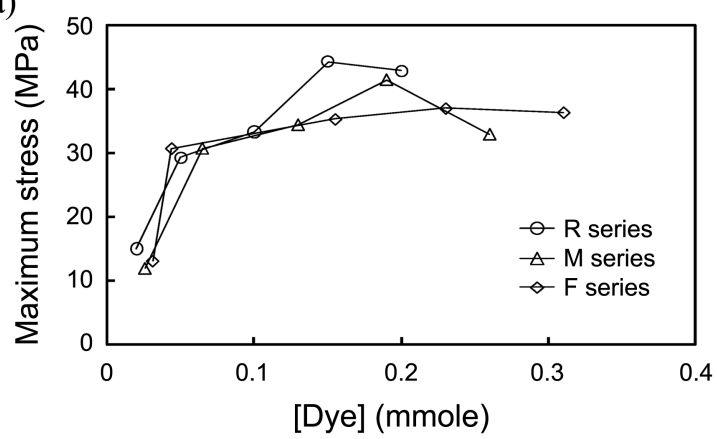

(b)

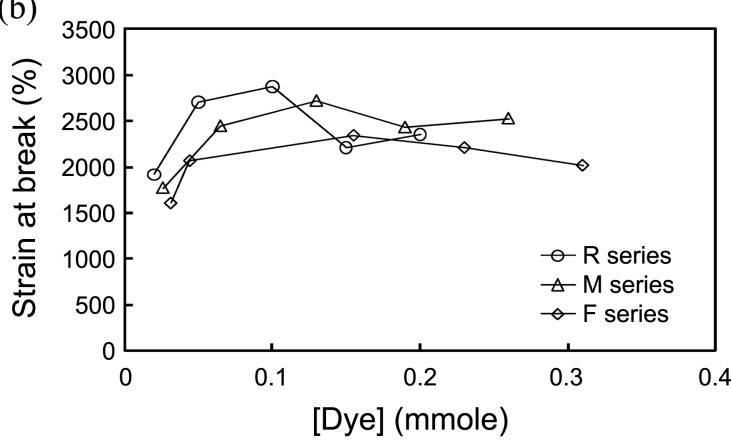

Figure 7. (a) maximum stress and (b) strain at break of the R, M and $\mathrm{F}$ series.

Results of tensile mechanical tests are summarized in Table 2. The improvement in both maximum stress and strain at break after dye-grafting was very interesting, and the reason could be that the grafted dyes reduced the molecular interaction between SMPU chains and thus increased the strain. The improvement in mechanical properties could be assured in the stress-strain curves of R, M, and F series (Figure 8).

Shape Memory Effect. A cyclic shape memory test was used to compare shape recovery and shape retention of dyegrafted SMPU in the range $\mathrm{T}_{\mathrm{m}} \pm 20^{\circ} \mathrm{C}$ (Figures 9 and 10). The $T_{m}$ of the soft segment was selected for shape memory tests instead of $\mathrm{T}_{\mathrm{g}}$ because $\mathrm{T}_{\mathrm{g}}$ was too low for temperature control using our apparatus, and is too low for practical applications. ${ }^{8,9}$ Shape recovery in the $\mathrm{R}$ series increased from $89 \%$ in R-1 to $91 \%$ in R-2 to $93 \%$ in R-5, and in the $\mathrm{M}$ series it increased similarly from $87 \%$ in $\mathrm{M}-1$ to $92 \%$ in $\mathrm{M}-3$ to $95 \%$ in $\mathrm{M}-5$. In F series, shape recovery remained high for all of the dyes contents: $97 \%$ in F-1 changed to $97 \%$ in $\mathrm{F}-3$ to $96 \%$ in F-5. All of the shape recovery of $\mathrm{R}, \mathrm{M}$, and $\mathrm{F}$ series were excellent compared with other competitive SMPs. Importantly, shape recovery did not diminish after repetitive cyclic tests in all of the $\mathrm{R}, \mathrm{M}$, and $\mathrm{F}$ series, and remained above or close to $90 \%$ for the entire range of dye content. For example, shape recovery of R-5 was $93 \%$ in the first cycle, and only reduced to $91 \%$ after the fourth cycle. The cyclic shape recovery test results suggested that the dyegrafted structure was highly reliable and extremely efficient in recovering their original shape under repetitive test conditions. Shape retention generally decreased as dye content increased: $90 \%$ in R-1 decreased to $78 \%$ in R-3 and then to $77 \%$ in $\mathrm{R}-5 ; 89 \%$ in $\mathrm{M}-1$ decreased to $84 \%$ in $\mathrm{M}-3$ to $86 \%$ in 
(a)

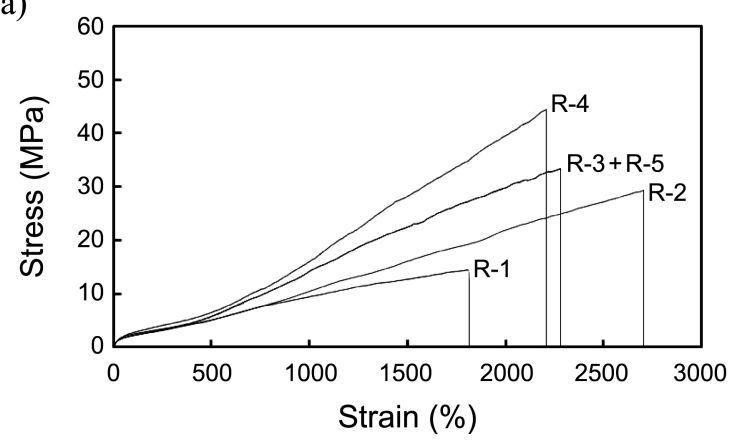

(b)

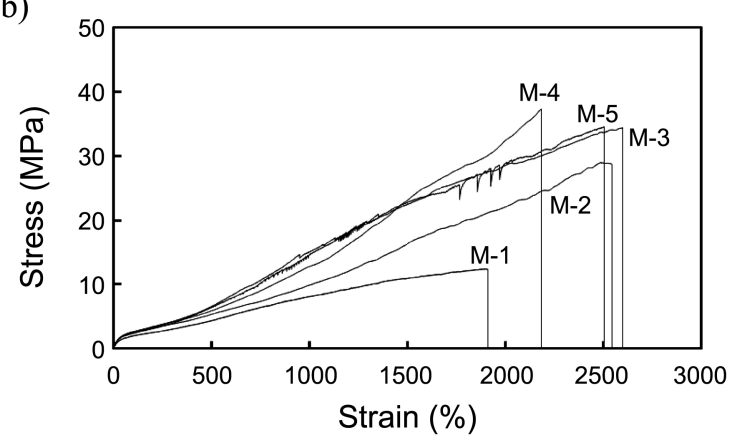

(c)

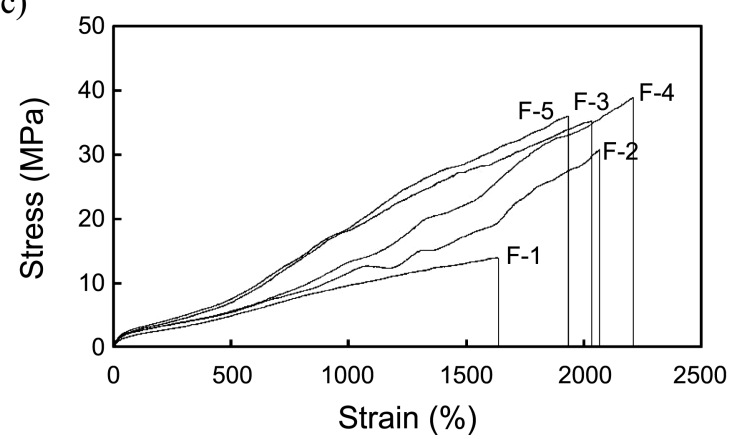

Figure 8. Stress-strain curves (a) R, (b) M, and (c) F series.

Table 3. Tensile mechanical properties

\begin{tabular}{ccc}
\hline $\begin{array}{c}\text { Sample } \\
\text { Code }\end{array}$ & $\begin{array}{c}\text { Maximum Stress } \\
\text { (MPa) }\end{array}$ & $\begin{array}{c}\text { Strain at Break } \\
(\%)\end{array}$ \\
\hline R-1 & 15 & 1916 \\
R-2 & 29 & 2703 \\
R-3 & 33 & 2874 \\
R-4 & 44 & 2210 \\
R-5 & 43 & 2351 \\
\hline M-1 & 12 & 1769 \\
M-2 & 31 & 2444 \\
M-3 & 35 & 2719 \\
M-4 & 42 & 2430 \\
M-5 & 33 & 2527 \\
\hline F-1 & 13 & 1608 \\
F-2 & 31 & 2067 \\
F-3 & 35 & 2342 \\
F-4 & 37 & 2209 \\
F-5 & 36 & 2018 \\
\hline
\end{tabular}

$\mathrm{M}-5$; $86 \%$ in F-1 decreased to $86 \%$ in $\mathrm{F}-3$ to $81 \%$ in $\mathrm{F}-5$. The shape retention experiment was conducted at very low (a)

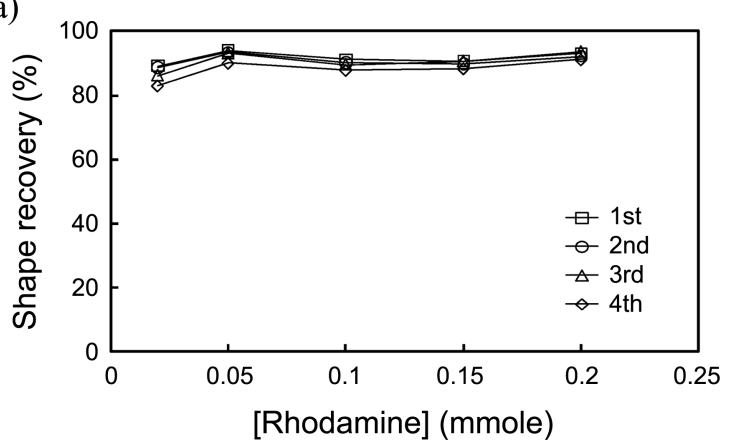

(b)

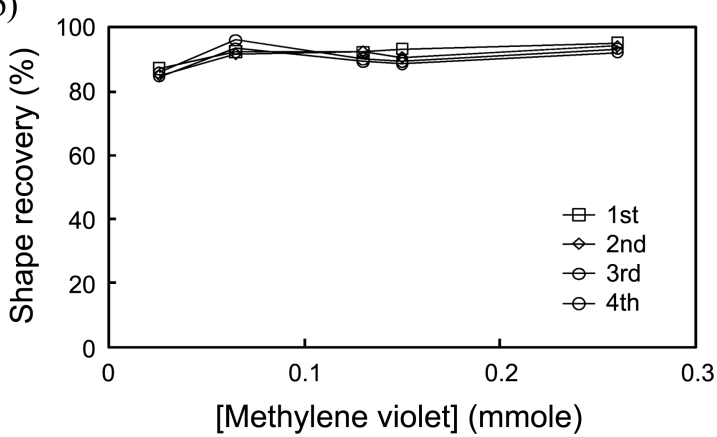

(c)

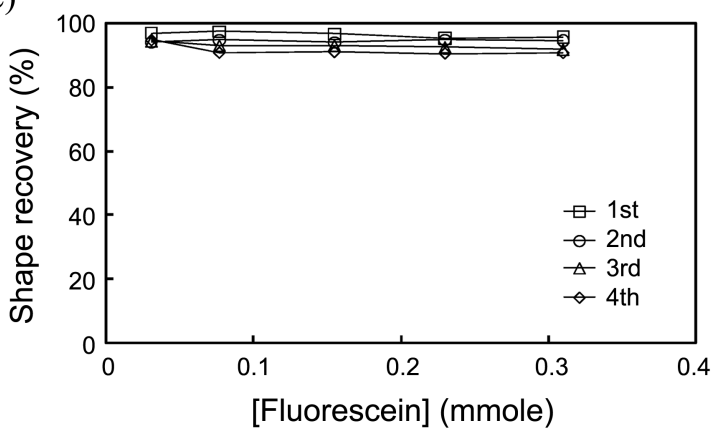

Figure 9. Shape recovery of the SMPU coupled with (a) rhodamine, (b) methylene violet, and (c) fluorescein.

temperature $\left(-20{ }^{\circ} \mathrm{C}\right)$, and tested the tendency of an SMPU to retain its shape against a shape recovering force. The high shape recovering force of dye-grafted SMPU may have reduced the shape retention property. Cyclic shape retention tests also demonstrated that the shape retention of R, M, and $\mathrm{F}$ series remained almost same after four cyclic tests: for example, the initial shape retention of M-5 (86\%) was almost same (88\%) after cycle four, and that of F-5 (81\%) was changed to $82 \%$ after cycle four. Shape memory test results are summarized in Table 4. Considering shape recovery, shape retention, and tensile mechanical results, R, $\mathrm{M}$, and $\mathrm{F}$ series, although grafted with fluorescent dyes, performed excellent compared to the previous SMPUs. The fluorescent dye grafting of SMPU chains did not interfere the molecular interaction and unexpectedly improved the performance in shape memory and mechanical properties.

Luminescence of SMPU. Luminescence spectra of each SMPU coupled with different dyes were analyzed to find that each spectrum showed the characteristic excitation and emission wavelength: $533 \mathrm{~nm}(\mathrm{ex})$ and $557 \mathrm{~nm}(\mathrm{em})$ for 
(a)

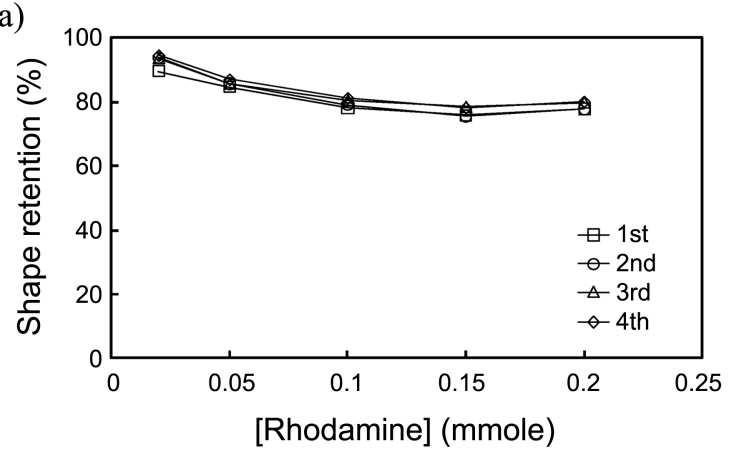

(b)

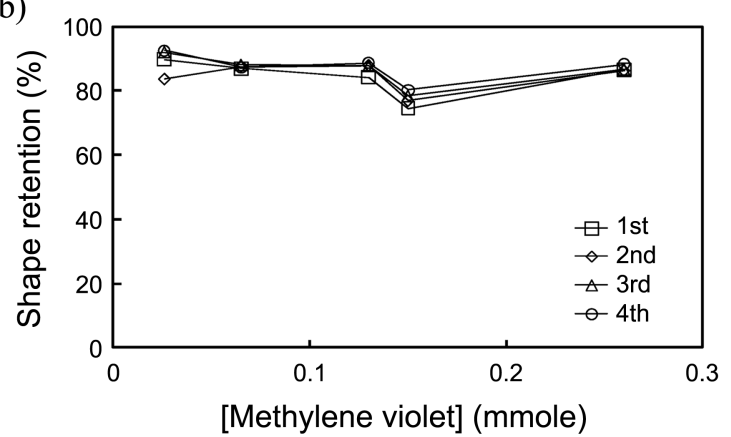

(c)

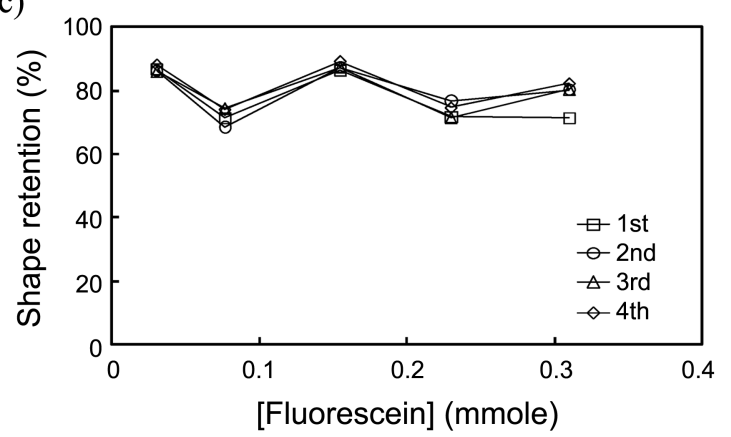

Figure 10. Shape retention of the SMPU coupled with (a) rhodamine, (b) methylene violet, and (c) fluorescein.

Table 4. Shape memory properties

\begin{tabular}{ccc}
\hline \multirow{2}{*}{$\begin{array}{c}\text { Sample } \\
\text { Code }\end{array}$} & \multicolumn{2}{c}{ Shape Memory $(\%)^{a}$} \\
\cline { 2 - 3 } & Recovery & Retention \\
\hline R-1 & 89 & 90 \\
R-2 & 94 & 85 \\
R-3 & 91 & 78 \\
R-4 & 91 & 76 \\
R-5 & 93 & 78 \\
\hline M-1 & 87 & 90 \\
M-2 & 93 & 87 \\
M-3 & 92 & 84 \\
M-4 & 93 & 75 \\
M-5 & 95 & 87 \\
\hline F-1 & 97 & 87 \\
F-2 & 97 & 71 \\
F-3 & 97 & 86 \\
F-4 & 95 & 72 \\
F-5 & 96 & 81 \\
\hline
\end{tabular}

${ }^{a}$ First cycle of shape memory results. (a)

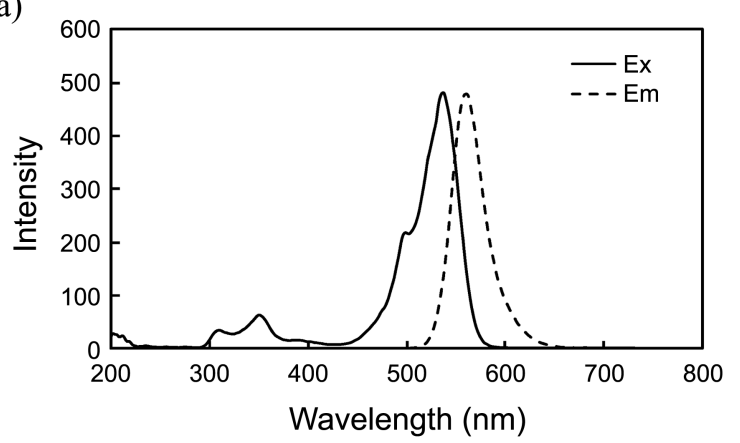

(b)

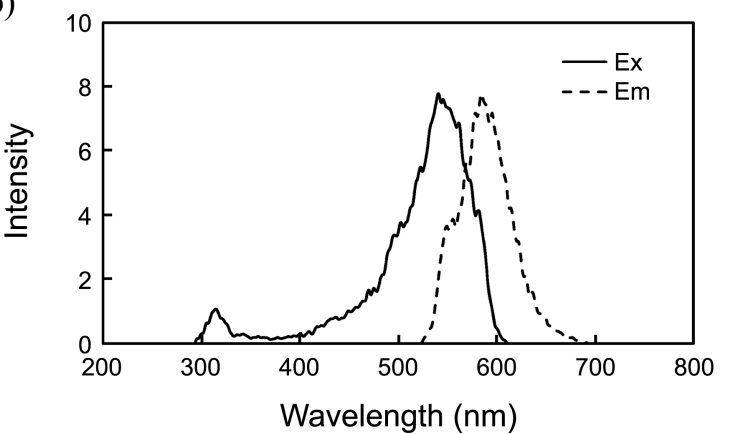

(c)

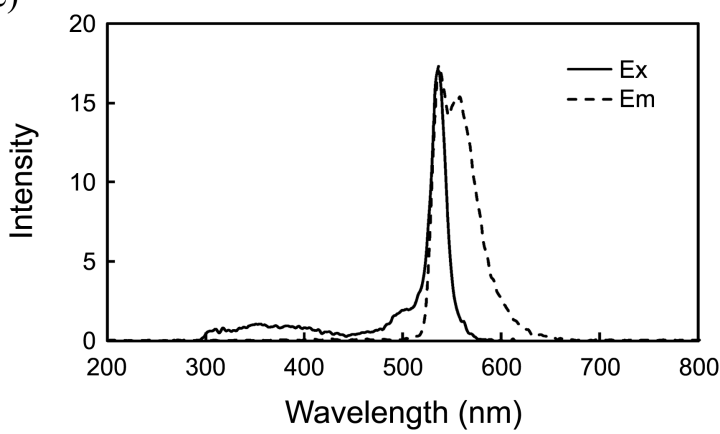

Figure 11. Fluorescence spectra of the SMPU coupled with (a) rhodamine, (b) methylene violet, and (c) fluorescein.

rhodamine-SMPU, $540 \mathrm{~nm}$ (ex) and $582 \mathrm{~nm}(\mathrm{em})$ for methylene violet-SMPU, and $535 \mathrm{~nm}(\mathrm{ex})$ and $552 \mathrm{~nm}(\mathrm{em})$ for fluorescein-SMPU (Figure 11). The characteristic dye structure was not affected by grafting to SMPU chain as judged from the fact that excitation and emission wavelength of dye-coupled SMPU was similar to those of free dyes. Luminescence phenomena of three dye-SMPUs were demonstrated in Figure 12 in which bright fluorescent light emission was obvious and dye distribution on SMPU was homogeneous. As the free dyes were removed from SMPU by washing with organic solvent, all of the luminescence emanated from the dyes grafted to SMPU. Although a few polymers grafted with dye were reported, grafting of dye to polyurethane backbone was newly introduced in this investigation. Finally, two specimens (R-5 and F-5) were tested for ion sensing ability against $\mathrm{Cu}^{2+}$ and $\mathrm{V}^{2+}$, respectively, by dipping them in $0.1 \mathrm{M}$ metal ion solution at room temperature for $1 \mathrm{hr}$. In Fig. 13, the surface of each specimen became darkened after contact with metal ions, suggesting the possibility of ion sensing by fluorescent PU. Other potential SMPU sensor 

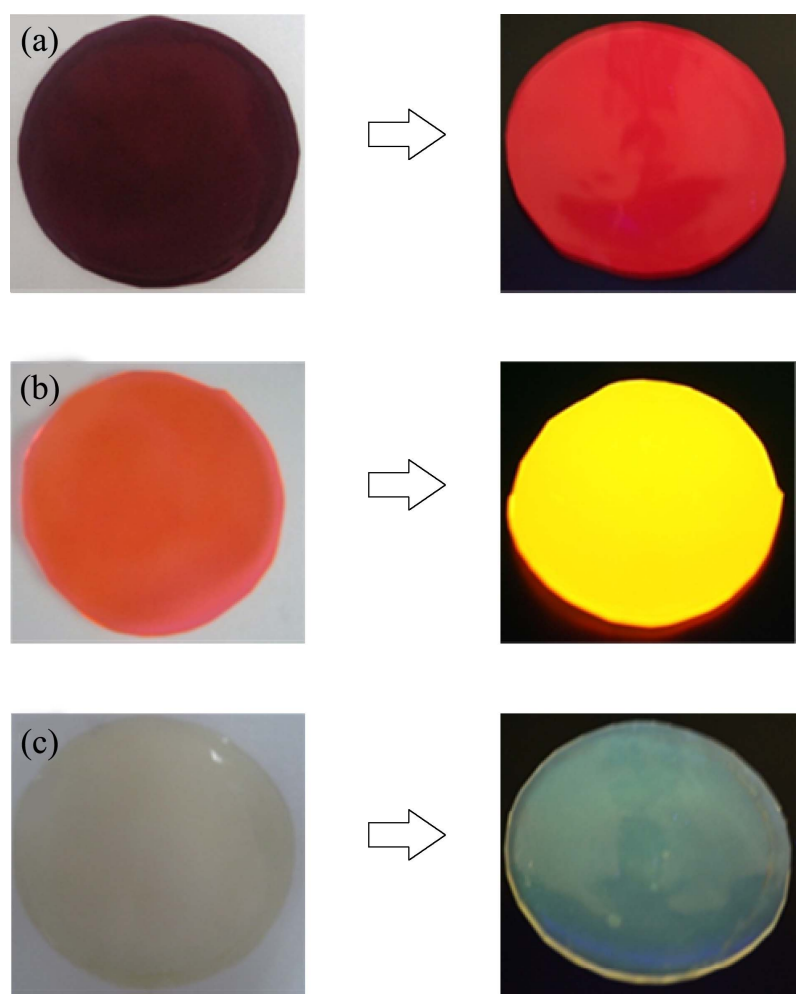

Figure 12. Fluorescent light emission under UV light from SMPU coupled with (a) rhodamine, (b) methylene violet, and (c) fluorescein.
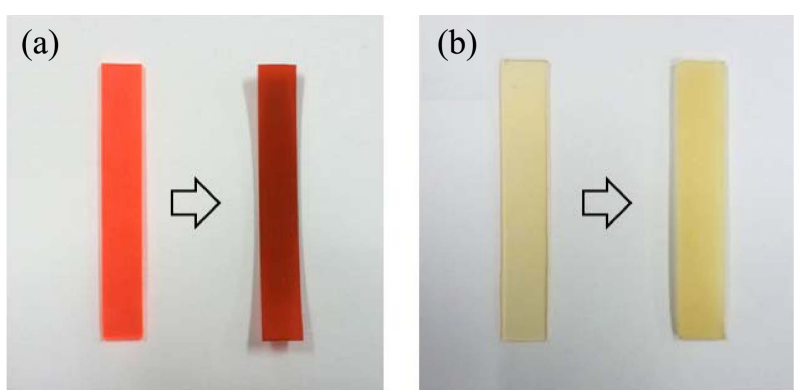

Figure 13. Ion sensing experiment of (a) R-5 for $\mathrm{Cu}^{2+}$ and (b) F-5 for $\mathrm{V}^{2+}$.

applications such as $\mathrm{pH}$ sensing, metal ion detection, and protein detection, became possible based on the grafting to SMPU technology.

\section{Conclusion}

The dye-grafted SMPU was investigated for its mechanical, shape memory, and luminescence properties. Characterization of the dye-grafted structure supported the fact that dye grafting did not affect the characteristics of SMPU chains. Three kinds of fluorescent dyes were tested for grafting. Shape recovery of all the series was over $90 \%$ and reproducible, although dye content was increased. The grafted dye was homogeneously distributed over SMPU surface and securely held to SMPU chains. The dye-grafted SMPU emitted the characteristic color under illumination as desired. This preliminary finding is possible by the grafting technology and will be useful for the development of the SMPU special functions.

Acknowledgments. This work was supported by grant from Inje University, 2011.

\section{References}

1. Takahashi, T.; Hayashi, N.; Hayashi, S. J. Appl. Polym. Sci. 1996, 60, 1061.

2. Chen, L. W.; Lin, J. R. J. Appl. Polym. Sci. 1998, 69, 1575.

3. Cho, J. W.; Lee, S. H. Eur. Polym. J. 2004, 40, 1343.

4. Rabani, G.; Luftmann, H.; Kraft, A. Polymer 2006, 47, 4251.

5. Wang, W.; Ping, P.; Chen, X.; Jing, X. Eur. Polym. J. 2006, 42, 1240.

6. Xu, J.; Shi, W.; Pang, W. Polymer 2006, 47, 457.

7. Razzaq, M. Y.; Anhalt, M.; Frormann, L.; Weidenfeller, B. Mater. Sci. Eng. A 2007, 471, 57.

8. Hu, J.; Yang, Z.; Yeung, L.; Ji, F.; Liu, Y. Polym. Int. 2005, 54, 854.

9. Yang, Z.; Hu, J.; Liu, Y.; Yeung, L. Mater. Chem. Phys. 2006, 98, 368.

10. Chun, B. C.; Chong, M. H.; Chung, Y. C. J. Mat. Sci. 2007, 42 , 6524.

11. Chun, B. C.; Cho, T. K.; Chong, M. H.; Chung, Y. C. J. Mat. Sci. 2007, 42, 9045.

12. Chung, Y. C.; Cho, T. K.; Chun, B. C. J. Appl. Polym. Sci. 2009, $112,2800$.

13. Chung, Y. C.; Lim, N. K.; Choi, J. W.; Chun, B. C. J. Intell. Mater. Sys. Struct. 2009, 20, 1163.

14. Cho, J. W.; Kim, J. W.; Jung, Y. C.; Goo, N. S. Macro. Rapid. Com. 2005, 26, 412.

15. Paik, I. H.; Goo, N. S.; Jung, Y. C.; Cho, J. W. Smart. Mater. Struct. 2006, 15, 1476.

16. Leng, J. S.; Lv, H. B.; Liu, Y. J.; Du, S. Y. Appl. Phys. Lett. 2007, 91, 144105

17. Schmidt, A. M. Macro. Rapid. Com. 2006, 27, 1168.

18. Leng, J. S.; Lan, X.; Liu, Y. J.; Du, S. Y.; Huang, W. M.; Liu, N.; Phee, S. J.; Yuan, Q. Appl. Phys. Lett. 2008, 92, 014104.

19. Leng, J. S.; Huang, W. M.; Lan, X.; Liu, Y. J.; Du, S. Y. Appl. Phys. Lett. 2008, 92, 204101.

20. Huo, F. J.; Su, J.; Sun, Y. Q.; Yin, C. X.; Tong, H. B.; Nie, Z. X. Dyes and Pigments 2010, 86, 50.

21. Dong, M.; Ma, T. H.; Zhang, A. J.; Dong, Y. M.; Wang, Y. W.; Peng, Y. Dyes and Pigments 2010, 87, 164.

22. Andreia, S.; Renato, E. F.; Reda, M. E.; Paulo, A. Eur. Polym. J. 2006, 42, 2270.

23. Nagao, D.; Anzai, N.; Kobayashi, Y.; Gu, S.; Konno, M. J. Coll. Inter. Sci. 2006, 298, 232.

24. Yang, S.; Meng, F.; Tian, He.; Chen, K. Eur. Polym. J. 2002, 38, 911.

25. Seckin, T.; Gultek, A.; Kartac, S. Dyes and Pigments 2003, 56, 51.

26. Makovec, D.; Campelj, S.; Bele, M.; Maver, U.; Zorko, M.; Drofenik, M.; Jamnik, J.; Gaberscek, M. Coll. Surf. A: Physicochem. Eng. Aspects 2009, 334, 74.

27. Chuan, D.; Wei, Y. X.; Wei, Y. L. J. Photochem. Photobio. A: Chem. 2005, 174, 15 .

28. Mohammad, T.; Morrison, H. J. Chrom. B 1997, 704, 265.

29. Kim, H. J.; Park, J. E.; Choi, M. G.; Ahn, S.; Chang, S. K. Dyes and Pigments 2010, 84, 54.

30. Nolan, E. M.; Ryu, J. W.; Jaworski, J.; Feazell, R. P.; Sheng, M.; Lippard, S. J. J. Am. Chem. Soc. 2006, 128, 15517.

31. Jang, Y. J.; Jun, E. J.; Lee, Y. J.; Kim, Y. S.; Kim, J. S.; Yoon, J. J. Org. Chem. 2005, 70, 9603.

32. Swamy, K. M. K.; Lee, Y. J.; Lee, H. N.; Chun, J.; Kim, Y.; Kim, S. J. J. Org. Chem. 2006, 71, 8626.

33. Shamansky, L. M.; Yang, M.; Olteanu, M.; Chronister, E. L. Mat. 
Lett. 1996, 26, 113.

34. Guan, X.; Liu, X.; Su, Z.; Liu, P. React. Funct. Polym. 2006, 66, 1227.

35. Cho, H. K.; Lone, S.; Kim, D. D.; Choi, J. H.; Choi, S. W.; Cho, J. H.; Kim, J. H.; Cheong, I. W. Polymer 2009, 50, 2357. (F polyester)

36. Uthirakumar, P.; Suh, E. K.; Hong, C. H.; Lee, Y. S. Polymer 2005, 46,4640 .

37. Nagasaka, M.; Yoshida, K.; Sato, K.; Hoshi, T.; Anzai, J. I. J. Coll. Inter. Sci. 2010, 348, 441.

38. Freij-Larsson, C.; Wesslen, B. J. Appl. Polym. Sci. 1993, 50, 345.
39. Tan, K.; Obendorf, S. K. J. Mem. Sci. 2006, 274, 150.

40. Archambault, J. G.; John, L. Coll. Surf. B: Biointer. 2004, 39, 9.

41. Hur, M. K.; Kwak, J. M.; Hur, T. A. Polymer (Korea) 1996, 20 , 392.

42. Petrovic, Z. S.; Javni, I.; Divjakovic, V. J. J. Polym. Sci. Part B: Polym. Phys. 1998, 36, 221.

43. Sekkar, V.; Gopalakrishnan, S.; Devi, K. A. Eur. Polym. J. 2003, 39,1281 .

44. Jane, S. R.; Sekkar, V.; Krishinamurthy, V. N. J. Appl. Polym. Sci. 1996, 62, 2317. 